\title{
NOTAS SOBRE O NOVO OCIDENTE DE ARTAUD: PENSAMENTO LIMINAR, EXPERIÊNCIA DA LIBERDADE E TEATRO RITUAL
}

Luiz Henrique Carvalho Penido* *luizpenido@gmail.com

Mestre em Letras pela UFMG, doutorando em Literatura Comparada também pela UFMG.
RESUMO: Este ensaio se dedica a articular o relato da viagem de Antonin Artaud ao México, em 1935 à inauguração de formas de pensamento liminar. novo ocidente é a palavra que designa precisamente um pensamento da despossessão em que se exercita plenamente a experiência da liberdade.

PALAVRAS-CHAVE: Antonin Artaud; novo ocidente; despossessão; liberdade.
RÉSUMÉ: Cet essai est dédié à articuler le récit de voyage d'Antonin Artaud au Mexique en 1935 avec l'inauguration des formes de pensée frontalières. Le nouveau occident est précisément le mot qui permet une pensée de la dépossession en exerçant pleinement l'expérience de la liberté.

MOTS-CLÉS: Antonin Artaud, nouveau occident, dépossession, liberté. 
1. Os tarahumaras, originalmente rarámuris chegando a sua form atual por corruptela espanhol săo um povo indigena que ocupa o sudoeste do estado de Chihuahua no México. Vários textos de Artaud fazem menção a esse povo, seus ritos e mitos como ponto de profusão de uma idéia viva de cultura em oposiçâo à decadência progressista da Europa moderna ocidental.

\section{O NOVO OCIDENTE}

Há muito se escreve sobre a viagem ao México, realizada nos idos de 1935 por Antonin Artaud, poeta e dramaturgo francês. Sem dúvida, grande parte dos acontecimentos narrados por ele permanece sob uma densa sombra de ceticismo e excentricidade. Pergunta-se, por exemplo, se a estadia no país do Tarahumaras ${ }^{1}$ teria por referência um deslocamento real para espaços aonde permanecem aspectos ancestrais do México ou uma éclatante fulguração da imaginação do poeta - ademais, adepto do uso dos stupéfiants e de toda e qualquer experiência alucinatória independente dos meios aplicados. Devemos deixar essas especulações de lado, de fato, se há algo essencial no pensamento da crueldade - independente das circunstâncias ou dos mitologismos pessoais que a sensibilidade contemporânea de uma civilização ávida e ao mesmo tempo aterrada com a excepcionalidade de alguns poucos homens desejou enfatizar para seus próprios fins - é a insignificância de determinados dualismos. Apreender a experiência de Artaud no país dos Tarahumaras só é possível se, por princípio e necessidade abandonamos a distinção entre a experiência real - aquela pretensamente derivada de acontecimentos concretos localizáveis no tempo e no espaço - e a experiência espiritual, sua dita contraparte, acontecimento em um espaço diverso e com suas próprias leis de afecção.
É por essa via de questionamento que se abrem as conferências presentes em Messages Révolutionnaires. Narrando a sua estada no México de aproximadamente um ano, entre 1935-1936, estada de um auto-exilado que busca a "exterioridade" do pensamento moderno europeu pela desconstrução dos dualismos que desde sempre trabalharam o pensamento e que fazem da cultura uma forma comercializáve da instrução, Artaud principia por afirmar: "car l'homme vraiment cultivé porte son esprit dans sons corps et c'est son corps qu'il travaille par la culture, ce qui équivaut à dire qu'il travaille en même temps son esprit." Por essa simples afirmação notamos a reversibilidade de qualquer afirmação que pretenda desvencilhar a experiência do homem Artaud, sua cartografia concreta, das cartografias imaginais pelas quais corpo e espírito se atravessam em espaços duplamente articulados. O país dos Tarahumaras de Artaud é antes de tudo uma cartografia dos efeitos, cartografia da efetividade de modos de vida não cindidos pelos binarismos do progresso, isto é, em resumo, uma cartografia de intensidades, independente das ocasiões de sua efetivação. Nesse contexto, os dualismos teriam por consequência apenas multiplicar os equívocos, aplicando os mesmos diagramas lógicos que o pensamento de Artaud tenta, justamente, se desvencilhar. Se a viagem ao México esboça a tentativa de uma volta ao pré-cartesianismo de uma civilização obscurecida pelos modos civilizatórios europeus, é necessário não ser europeu demais,

\begin{tabular}{|c|c|c|}
\hline BELO HO & v. 19 & \\
\hline
\end{tabular}


3. "En Europe, à côté des prophetes du nouvel Occident, Spengler, Scheller et Heidegger, Spengler, Scheller et Heidegger, on trouve des petits maitres de la décadence qui, comme Keyserling, ne sont rien d'autre que des commis voyageurs, amateurs d'un hindouisme de pacotille et, passant toute mesure, des papillonneurs ARTAUD, 2008, p. 706. isto é, é necessário tensionar o nosso próprio pensamento aos desequilíbrios que uma forma liminar de pensamento invoca, começando pela irrelevância de determinadas categorias clássicas que fundamentam o pensamento filosófico de determinados "maîtres de la décadence".

Uma dupla questão então se delineia para nós leitores de Artaud: de um lado é preciso ler Artaud fora dos diagramas formativos dos sistemas ocidentais - os dualismos, as oposições, os contrapontos, em resumo, as figuras ocidentais de grave parcela do pensamento - de outro, como não podemos de fato pretender um total desligamento, é preciso tensionar o nosso próprio para atingir essas curvas do pensamento da crueldade que garantem tanto a sua eficácia concreta quanto a relevância de tal pensamento. De um lado desenvolve-se uma questão estratégica, isto é, a impossibilidade do desligamento implica a necessidade de aplicar com eficácia os recursos de que se dispõe; de outro uma questão tática, uma vez em movimento, devemos tensionar as formas e os meios para atingir a zona de indecidibilidade em que o nosso pensamento mais familiar parece articular algo estranho, momento em que o exílio atinge a sua efetividade como espaço interminavelmente outro. Mais ainda, a questão tática deve permanecer como a reserva de negatividade radical atuando no desvanecimento dos efeitos de poder que as circunstâncias estratégicas nos colocam sob a constante iminência.
Feitas as ressalvas, podemos nos perguntar: se Artaud não pretende acrescer mais um sistema filosófico, estético, lógico, exotérico aos inúmeros discursos europeus nos quais ele reconhece a decadência da cultura, mas sim, realizar a própria cultura em sua força, isto é, exatamente no ponto em que os sistemas de pensamento se tornam estéreis e as distinções deslizam continuamente uma em direção a outra criando uma cultura da ação e só reconhecível na ação, como pensar o auto-exílio, a linha de fuga dos Tarahumaras de forma a não transformá-los em uma dialética da resistência e da opressão? Mais ainda, como pensar em termos de anáfora absoluta - segundo Artaud a idéia de arte no ocidente já nasce separada da vida, é preciso voltar às vésperas de seu nascimento - um movimento de fuga que reencontra nos escombros de um povo - os outrora numerosos rarámuris - o negativo da Europa, aquilo que desde sempre esteve fora de jogo nas realizações do pensamento filosófico e artístico europeu? Em outras palavras, como pensar aquilo que sempre foi o im-pensável axiológica e estruturalmente no contexto dos sistemas de pensamento europeu, tendo por referência um povo arruinado pelo processo civilizatório e que sobrevive de sua invisibilidade, sem correr o risco de repetir as mesmas questões, de entregar-se aos mesmos fluxogramas de pensamento, sendo o próprio exílio cifrado por um código comum que colocaria em risco tanto as ambições quanto 
4. Deixemos claro que em Artaud a questão estratégica, ao que nos parece, é apenas o resquício da questão tática, aquilo que náo pudemos nos desvencilhar totalmente. De fato, se observarmos as teses de $O$ teatro e seu duplo veremos que se trata de uma radicalização das Messages Révolutionnaires, no entanto, para os objetivos do presente ensaio basta notar que ele reconhece a permanência de determinada atividade estratégica em detrimento de toda a radicalização proposta pelo teatro crue

5. 1988. o objeto ambicionado, isto é, iterando forçosamente a concepção sujeito-objeto que deu origem a tantos exotismos?

Parecem ser essas as questões que perpassam com alguma insistência as Messages Revolutionnaires bem como fundamentam grande parte das críticas de Artaud e a necessidade desse primeiro deslocamento espacial para as Américas: a busca da legitimidade de um pensamento simultaneamente fronteiriço e exilado, nem subjugado pela geografia das epistemologias modernas, nem totalmente indiferente a elas, mas, exatamente, colocando-as em um contínuo desequilíbrio garantido pela reserva de negatividade. Artaud chama a esse agenciamento a "realização da metafísica" ou simplesmente "teatro da crueldade" ${ }^{4}$, nós situaremos tal pensamento como aquele situado nos limites de uma experiência da liberdade, segundo o interessante ensaio de Jean-Luc Nancy em L'expérience de la liberté.

\section{A EXPERIÊNCIA DA LIBERDADE}

É preciso antes de tudo entender a genealogia daquilo que aqui nomeamos experiência da liberdade, bem como a pertinência de significação que nos faz preferi-lo às próprias expressões de Artaud. Trata-se de apontar para determinada herança heideggeriana disseminada no pensamento contemporâneo que levaremos em consideração nesse ensaio com o objetivo de descrever as condições de possibilidade de um pensamento exilado e fronteiriço, sob o signo de uma autêntica experiência da liberdade. O primeiro passo é apreender no pensamento contemporâneo, para além dos vários existencialismos e essencialismos, fundados sobre a ideia de precedência de um dos termos sobre o outro em relações duais - a existência para a essência como pensa Sartre, iterando os fluxogramas mentais familiares aos sistemas de pensamento historicamente determinados pelo seu pertencimento metafísico - a tendência a delinear um espaço quiasmático no qual o primeiro termo é a efetuação do segundo em relações não hierarquizáveis.

Sob essa perspectiva, conseguimos observar uma proliferação de conceitos liminares nas mais variadas disciplinas, não apenas aquelas nas quais a filosofia teria uma incidência direta, mas também nas disciplinas estabelecidas sobre bases forçosamente pragmáticas. Pensemos, por exemplo, na incidência de inúmeros desconstrucionismos na linguística estrutural rastreando menos um acontecimento epocal - o interesse renovado pela linguagem - do que a denúncia de sua irredutível historicidade - a dependência de conceitos histórico-metafísicos. É através da desconstrução de dualismos caros à linguística estrutural como os de significante/significado, eixo sincrônico/diacrônico, escrito/oral, etc., todos denunciando uma determinada grade de pensamento, que se desenvolveram - pensemos no caso Derrida - conceitos 
6. DERRIDA, 2001, p. 32.

7. “[...] indecidíveis, isto é, unidades de simulacro, 'falsas' propriedades verbais, nominais ou semânticas, que não se deixam mais compreender na oposição filosófica (binária) e que, entretanto, habitam-na, opõe-lue, esistência, desorganizam-na, mas, sem nunca constituir um terceiro termo, sem nunca dar lugar a uma solução nu forma diát́tica especulatica" DERRIDA, . 49.

8. CASTRO, 2007, p. 95 liminares, fronteiricos ou simplesmente atravessados por uma radical negatividade como os de "suplemento", "espaçamento", ou ainda, a différance como jogo sistemático das diferenças. Em todos os conceitos mencionados o índice negativo - "sínteses e remessas que impedem que, em algum momento, em algum sentido, um elemento simples esteja presente em si mesmo e remeta apenas a si mesmo"6-aponta para a persistência de indecidíveis ${ }^{7}$ em uma economia conceitual na qual a reserva de negatividade traça as suas condições de possibilidade.

Pensemos também nas ciências humanas, particularmente a antropologia, quanto à busca de uma reproblematização interna dos seus processos de construção do saber - necessidade epistemológica e, por conseguinte ético-política -, a substituição da metáfora e da representação pela metonímia a indicialidade e a literalidade como maneira de "privilegiar a pragmática sobre a semântica, e de valorizar a parataxe sobre a sintaxe." Assim, determinados conceitos verticalizados como os de filiação e influência - são substituídos com alguma produtividade por conceitos transversais como os de aliança e contaminação, isto é, devires negativos ou mais exatamente a negatividade de todo devir que se desenvolve no espaço não limitável do trânsito entre dois termos não presentes em si.

sobre esse campo de propostas que desejamos inscrever o pensamento nos limites da experiência da liberdade. Em primeiro lugar, o que significa pensar em relação a essa liberdade? O que significa, implicado nas condições de possibilidade de todo pensamento, a liberdade ou o pensar livre? Ora, se como demonstramos a contemporaneidade arrisca forçar o pensamento para conceitos liminares proliferando os espaços quiasmáticos, é preciso que também a palavra "liberdade" não designe nem uma essência servindo de fundamento aos agenciamentos de um saber centrado, nem se refira a liberdades particulares, "existências", pequenos consentimentos pontuais. Nem essência, nem existência, mas a dinâmica de sua irredutibilidade. Se, como dissemos, os dualismos são assediados por essa nova configuração, a conseqüência é que a experiência da liberdade se converta no abandono, na liberdade do abandono que advém do fato de a existência se constituir a si própria como essência: "Car la liberté ne peut plus être ni « essentielle », ni « existentielle », mais elle est impliquée dans le chiasme de ces concepts : il faut penser ce qui fait l'existence, en son essence, abandonnée à une liberté, libre pour cette abandon, livrée a lui et en lui disponible". ${ }^{9}$

Pensar aqui significa, precisamente, vergar-se sobre o imperativo último da liberdade, a consequência do deslizamento dos binarismos para outra cosmologia do pensamento, isto é, não se trata da criação de um terceiro termo pela fusão dos 
termos em questão, mas, contrariamente, da impossibilidade de qualquer termo que seja, a sua mais completa liberdade. Nesse sentido, a liberdade é a pura negatividade que garante e ao mesmo tempo desterra qualquer efeito de positividade.

Todos os conceitos liminares por nós mencionados nos dois exemplos precedentes, o enclausuramento da linguística e a abertura da antropologia, são conceitos fortemente instituídos nas premissas da experiência da liberdade, primeiro porque são sempre reportados a um espaço centrífugo que os traciona para fora de si mesmos: a différance é esse movimento no processo da significação; a aliança e a contaminação, revogando os efeitos de poder dos discursos antropológicos fundados no comparativo de termos positivos, são por sua vez as responsáveis por arrastar a própria disciplina antropológica para fora do recurso ao modelo familiar da filiação e da influência, forçando ao duplo estranhamento. Segundo, e num gesto duplo, fazem da própria liberdade a consistência de um pensamento, isto é, fazem da liberdade possibilidade crítica que subjaz os discursos centrados - no caso da linguística a denúncia dos vários logocentrismos e fonocentrismos que comandam os nossos processos cognitivos, na antropologia, e mais especificamente atingindo o campo ético-político, os efeitos de poder dirigindo o olhar sob a forma do exótico no seu sentido original de invisibilidade, de não visto.

\section{DA ARTE AO RITO}

Uma vez delineados os traços gerais da experiência da liberdade, essa obsessão de nosso tempo presente tanto nos escritos de Artaud quanto em grande parte do pensamento contemporâneo que tenta se despedir de velhos hábitos de pensamento, seria interessante retomar aqui, posicionados em relação a tal experiência, as teses sobre o teatro de Antonin Artaud. A Correspondance avec Jacques Rivière, publicada pela primeira vez em 1924, dá-nos um ponto de entrada na questão da liberdade. Trata-se de uma troca de cartas entre o editor francês e o poeta que se estende por pouco mais de um ano, entre 1923-1924, versando sobre, particularmente, as questões da escrita e da inspiração. Particularmente interessante é o fato de que em alguns trechos, desenvolva-se uma vigorosa reflexão da negatividade, a essa altura, a angústia de um homem atormentado pelo duplo que se oferece a cada instante:

Je souffre d'une effroyable maladie de l'esprit. Ma pensée m'abandonne, à tous les degrés. Depuis le fait simple de la pensée jusqu'au fait extérieur de sa matérialisation dans les mots. Mots, formes de phrases, directions intérieures de la pensée, réactions simples de l'esprit, je suis à la poursuite constante de mon être intellectuel. Lors donc que je peux saisir une forme, si imparfaite soit elle, je la fixe, dans la crainte de perdre toute la 
pensée. Je suis au-dessous de moi-même, je le sais, j’en souffre, mais j’y consens dans la peur de ne pas mourir tout à fait. ${ }^{10}$

Para Artaud, a criação é a conflagração constante que se desenvolve nos limiares do pensamento e da escrita - escrita grafemática no caso presente, mas logo se estendendo às vá rias inscrições do corpo, do ritmo e do som. Não há, para ele ato de criação que não seja um risco, que não seja uma invectiva contra todo o pensamento e o coloque em constante risco de desvanecimento. Parece que Artaud reconhece, no pensamento que o abandona, a própria força quiasmática do entrevero, da forçosa coincidência que advém do fato que pensar é já inscrever algo e que o pensamento não pode desenvolver-se sobre a forma purificada de um em si sem que para isso trace, crie sulcos, formas, inserções. Livre por esse abandono, livre pela ausência de fundamento oferecido pelo espaço quiasmático no qual se atravessam as involuções do pensar-já-escrita, a essa altura de sua experiência criadora, o poeta pode apenas lamentar a falta de precedência de um pelo outro o que daria a ele a tarefa de um contínuo ajustamento e a meta palpável de busca da simetria absoluta.

É que, nesse momento da sua obra, a escrita é uma luta mal conduzida, ou pelo menos desde já condenada, contra o silêncio e o nada. Será que esse pensamento-trapo que vem da absoluta ausência em que se debate o pensamento chega LITERALMENTE a existir, pergunta-se Artaud?
Será que a fuga do pensamento, esse estado de abandono, indica a impossibilidade do pensamento em geral, a reserva indeterminada de uma coisa qualquer que me ultrapassa para me destruir? «ll y a donc une chose qui détruit ma pensée ; un quelque chose qui ne m'empêche pas d'être ce que je pourrais être, mais qui me laisse, si je puis dire, en suspens. Un quelque chose de furtif qui m'enlève les mots que j'ai trouvés $\gg^{11}$. E a constatação que arrasta a angústia e o dilaceramento, a medida de despossessão que dão o tom desses primeiros escritos de Artaud. Palavras como effondrement, érosion, non-possession, séparation, éparpillement são constantemente utilizadas para dar a medida desta, então, "má liberdade", principalmente, o impulso para pensar cada uma das estratificações finais do pensamento sob todas as localizações da expressão e da forma, isto é, a necessidade de uma materialização efetiva.

Os escritos de Artaud dessa primeira fase de sua obra são uma contínua análise desses pequenos acontecimentos do pensamento e do corpo, da intransigência desses espaços duplicados em que se debate o ato criador, sempre aquém e além do ponto preciso, da estratificação exemplar. A angústia desses estados é, precisamente, a experiência da liberdade como a definimos anteriormente: é porque reconhece a liberdade desse abandono infinito como falta, despossessão arrancando as suas palavras e o impedindo de criar o que

EM TESE $\quad$ BELO HORIZONTE $\quad$ v. $19 \quad$ N. $1 \quad$ JAN.-ABR. $2013 \quad$ PENIDO. Notas sobre o novo ocidente de artaud: pensamento liminar [...] $\quad$ P. 102-111


quer que seja, impedindo-o de obrar um sentido, na dupla acepção da palavra, enfim, é por esse estado de coisas que advém a angústia, intuição dessa falta central como perda da substância vital, essencial.

Sous cette croûte d'os et de peau, qui est ma tête, il y a une constance d'angoisses, non comme un point moral, comme les ratiocinations d'une nature imbécilement pointilleuse, ou habitée d'un levain d'inquiétudes dans les sens de sa hauteur, mais comme une (décantation)

\section{à l'antérieur,}

comme la dépossession de ma substance vitale,

comme la perte physique et essentielle

(je veux dire perte du côté de l'essence)

$$
\text { d'un sens. }{ }^{12}
$$

A despossessão, palavra recorrente nos escritos desse período inaugura a experiência da liberdade como angústia, mas, igualmente, abre o espaço de uma verdadeira vontade de potência que se vai desenvolver nas teses sobre o teatro. Entendamo-nos: a virada metafísica da obra de Artaud se dá exatamente quando reconhece nessa negatividade que obseda o sentido e o ato de criação a única e verdadeira oportunidade de criação, isto é, a angústia da fase inicial é substituída pelo acontecimento teatral da crueldade, o abandono operado pela liberdade se converte no espaço infinito da criação de campos liminares, a angústia da cisão essência/ existência é deslocada pela liminaridade do puro devir.

No entanto, tal virada só é possível a partir do desenvolvimento de uma verdadeira cartografia, do surgimento de um novo ocidente firmado nos espaços "obscenos" do novo mundo. Referimo-nos anteriormente à desconstrucão dos dualismos como essa primeira invectiva, agora é necessário voltar a ela para enfatizar a dimensão da experiência da liberdade: se a proposta de proliferação dos espaços fronteiriços começa pela desconstrução dos dualismos e deve a esse movimento a sua efetividade, o teatro, fundado em uma comunidade de ritos - herança da experiência nas Américas - é a própria fronteira e o próprio exílio, a absoluta liberdade.

A convivência no México conduz Artaud a intuir os embaraços da idéia europeia de arte, fundada em sistemas representativos em que se iteram indefinidamente os conflitos humanos, arte descarnada e passiva que funciona na diferença entre a pura experiência intelectual e a suspensão momentânea da descrença. Terminado o espetáculo segue o homem o seu curso ordinário sem fissuras. O dualismo entre arte e vida permite essa experiência anestésica, no entanto, consumando a arte no rito - afinal, não há arte ameríndia que não tenha sido um dispositivo mágico e encantatório 
13. QUICILI, 2004, p. 38.

14. ARTAUD, 2006, p. 2 ou que tenha funções meramente de fruição - desfaz-se a distinção, por sua vez, entre a arte e a vida.

A arte é a própria vida na medida mesma em que deve desencadear "uma vivência de natureza singular, 'mítica' mas num sentido arcaico e primitivo" ${ }^{\prime 3}$, ou seja, em um sentido ainda não afetado pelas formas representativas da arte ou pelas formas burguesas do divertimento. $\mathrm{O}$ rito como espaço fundador desfaz por sua vez as separações, os dualismos, porque teria a capacidade de unificar a experiência em uma explosão de afecções em que nenhum objeto, nenhum movimento, nenhum grito ou inscrição teria valor simplesmente contemplativo. É quando a arte se torna ação e deve entrar pela pele proliferando pelos espaços cotidianos - arte em que palavra faca deve cortar, em que o gesto brusco deve estremecer - que se percebe a dimensão ritual do teatro da crueldade, assim como, a inconsistência da ideia europeia de arte oposta à vida, de civilização oposta à cultura.

É preciso insistir na idéia da cultura em ação e que se torn em nós como que um novo órgão, uma espécie de segundo espírito: e a civilização é cultura que se aplica e que rege nossas ações mais sutis, o espírito presente das coisas; e é artificial a separação entre a civilização e a cultura, com o emprego de duas palavras para significar uma mesma e idêntica ação. ${ }^{14}$
O teatro da crueldade de Artaud seria o dispositivo metafísico, ritual, para unificar as duas pontas da cadeia porque extrapolaria as formas de normatização, negando o espaço que lhe é destinado na cultura dos bens simbólicos, da contemplação estética passiva e se transformando no ritual generalizado de uma civilização/cultura renascida.

\section{CONSIDERAÇÕES FINAIS}

É preciso traçar o esboço geral do que até aqui foi dito para que tenhamos uma ideia, ainda que provisória, do que tentamos demonstrar nesse ensaio. Em um primeiro momento demonstramos a insatisfação de Artaud com o pensamento artístico europeu. Tratava-se, naquele momento, de marcar a sua busca pelo negativo do ocidente bem como a obsessão pelos espaços liminares deste para realizar de fato um pensamento inaugural e não mais cindido pelos dualismos, pelas configurações mais ou menos estratificadas dos sistemas e dos hábitos. É nessa perspectiva que tomamos a viagem para o país do Tarahumaras como a primeira tentativa de deslocamento das grades de contenção do pensamento metafísico ocidental. Artaud intuía que, para sair do ocidente, era urgente voltar-se para os espaços marginais, ignorados do novo mundo de forma a fundar-se não mais em uma dialética da negação, mas, contrariamente, proliferar esses espaços no próprio pensamento europeu. 
Em um segundo momento e, definindo a estratégia/tática de Artaud - bem como a nossa, já que era necessário tensionar o próprio pensamento para alcançar a amplitude dessas linhas alternativas - como a tentativa de uma verdadeira experiência da liberdade na acepção de Jean-Luc Nancy, deslizamos o próprio pensamento dualista para o seu limite, isto é, o momento estratégico em que as formas que temos parecem não mais se conterem e propõem novos agenciamentos. Ora, se o próprio Artaud teme não conseguir alçar-se para fora das questões artísticas europeias é porque pressente esse seu pertencimento e age conscientemente contra ele dentro daquilo que chamamos questão tática e questão estratégica. Nesse sentido, a experiência da liberdade consuma dentro da tradição mesma que quer negar, um espaço escorregadio no qual se abre a possibilidade de uma nova cosmologia do pensamento.

Em um último momento, pudemos observar como o próprio Artaud vai da angústia que advém consciência dessa necessidade dúbia - agir autenticamente no abandono que nos dá um pensamento fronteiriço, liberto - para a criação de um dispositivo que possa realizá-lo verdadeiramente. Esse dispositivo é o teatro da crueldade: fundando-se não mais no panteão europeu da arte, mas "retrocedendo" para as formas rituais, ele pretensamente apagaria a mais reticente cisão do pensamento europeu, a arte e vida, o pensamento e a vida, a cultura e a civilização. Doravante, para Artaud, a liberdade do abandono se torna ocasião para criação e a criação se torna ela própria dinâmica da vida porque colhe seus efeitos em um acontecimento total. Não há mais arte ou pensamento que não seja vida, e o risco que advém dessa posição na qual deslizam continuamente existência e essência, se converte em potência reativando a função verdadeira do pensamento e da arte, isto é, uma arte e um pensamento que sejam ação, o verdadeiro sentido da experiência da liberdade.

\section{REFERÊNCIAS}

CASTRO, Eduardo Viveiros de. "Filiação intensiva e aliança demoníaca" In: Novos Estudos - CEBRAP, n. 77, 2007.

DERRIDA, Jacques. Posições. Belo Horizonte: Autêntíca, 2001.

MOREIRAS, Alberto. A exaustão da diferença: a política dos estudos culturais latino-americanos. Tradução Eliana Lourenço de Lima Reis/ Glauce R. Gonçalves. Belo Horizonte. Ed. UFMG, 2001.

NANCY, Jean-Luc. L'expérience de la liberté. Paris: Galilée, 1988.

QUICILI, Cassiano Sydow. Antonin Artaud: teatro e ritual. São Paulo: Annablume, 2004.

VATTIMO, Gianni. O fim da modernidade. São Paulo: Martins Fontes, 2007. 